\title{
Exosomes in specific fractions of the boar ejaculate contain CD44: A marker for epididymosomes?
}

Manuel Alvarez-Rodriguez, Stefan Ljunggren, Helen Karlsson and Heriberto Rodriguez-Martinez

The self-archived postprint version of this journal article is available at Linköping University Institutional Repository (DiVA):

http://urn.kb.se/resolve?urn=urn:nbn:se:liu:diva-161828

N.B.: When citing this work, cite the original publication.

Alvarez-Rodriguez, M., Ljunggren, S., Karlsson, H., Rodriguez-Martinez, H., (2019), Exosomes in specific fractions of the boar ejaculate contain CD44: A marker for epididymosomes?, Theriogenology, 140, 143-152. https://doi.org/10.1016/j.theriogenology.2019.08.023

Original publication available at:

https://doi.org/10.1016/j.theriogenology.2019.08.023

Copyright: Elsevier (12 months)

http://www.elsevier.com/

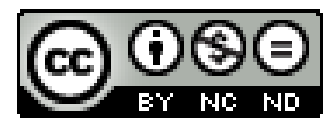


Exosomes in specific fractions of the boar ejaculate contain CD44: a marker for epididymosomes?

Manuel Alvarez-Rodriguez ${ }^{1 *}$, Stefan A Ljunggren ${ }^{2}$, Helen Karlsson ${ }^{2}$, Heriberto Rodriguez-Martinez ${ }^{1}$

${ }^{1}$ Department of Clinical \& Experimental Medicine (IKE), BHK/O\&G Linköping University, SE-58185 Linköping, Sweden.

${ }^{2}$ Occupational \& Environmental Medicine Centre, Linköping University, SE-58185 Linköping, Sweden.

\section{Corresponding author:}

E-mal: manuel.alvarez-rodriguez@liu.se 


\section{Abstract}

Seminal plasma (SP) is a complex fluid containing proteins, peptides, enzymes, hormones as well as extracellular vesicles (EVs). The SP interacts with spermatozoa and the inner cell lining of the female genital tract, adsorbing proteins and exosomes that modulate sperm functions and female immune responsiveness. In the present study, boar sperm-free SP was studied using flow cytometry (FC) after membrane tetraspanins (CD9, CD63 and CD81) and membrane receptor CD44 marking of non-enriched (whole SP) or gradient fractions enriched through two-step discontinuous KBr-densitygradient ultracentrifugation, in whole ejaculate or in selected ejaculate fractions. The results, evaluated by transmission electron microscopy, confirmed the presence of exosomes in all fractions of the pig SP. Noteworthy, these pig SP-exosomes were CD44-bearing when analyzed by FC, with bands detected by western blotting (WB) at the expected $85 \mathrm{kD}$ size. The two-step discontinuous $\mathrm{KBr}$-density-gradient ultracentrifugation enriched the population of exosomes in two specific gradient fractions, indicating exosomes (either prostasomes or epididymosomes) could be separated from low-density lipoprotein (LDL) but they co-sediment with the highdensity lipoprotein (HDL)-bearing fraction. The findings pave for the selective isolation of exosomes in functional studies of their function when interacting with spermatozoa, the oocyte and/or the female genitalia, including hyaluronan-CD44 interplay.

Key words: seminal plasma, ejaculate fractions, gradient ultracentrifugation, exosomes, lipoproteins, tetraspanins, western blot, CD44, pig. 


\section{Introduction}

Seminal plasma (SP), the extracellular medium where mammalian spermatozoa are suspended in, derives from the testis, epididymis and accessory sexual glands [1,2]. The SP has a complex composition with important functions, from modulating sperm transport, affecting sperm motility and function [1,3] including fertilizing capacity [4], to the induction of gene regulation of the immune system of the female towards tolerance of the foreign paternal spermatozoa and accompanying proteins $[5,6]$. Hormones, as well as hundreds of proteins and peptides (including antioxidative enzymes and cytokines [7-10], are present $[10,11]$ to influence fertility, apparently for their interaction with the female immune function $[5,12]$ via post-translational or posttranscriptional effects on proteins respectively RNA of the female; changes that would continue evolving along the female transcriptome and proteome to render further responses [13]. The mammalian SP also contains extracellular vesicles (EVs), spherical membrane-coated structures released as part of the genital cell secretome [14]. The EVs are classified by size, as either exosomes $(30-100 \mathrm{~nm}$ in diameter) or microvesicles (100-1000 nm diameter) [14-18]. In SP, exosomes are also classified by point of origin, as epididymosomes, prostasomes or even vesiculosomes [19-21].

Exosomes are considered to maintain homeostasis, and their modulating function in the SP has been related to the transfer of proteins but also other molecules including small regulatory non-coding RNAs to the sperm surface $[21,26]$. This transfer affects sperm function in pigs, from sperm maturation to zona pellucida binding [22-25], apparently by infiltration into the sperm membrane [26]. Exosomes isolated from the sperm-rich fraction (SRF) of the pig ejaculate induced expression changes in immune-related genes when applied to uterine epithelial cells in vitro, similar to the changes observed in the endometrium of mated sows [21]. Such changes could presumably be exerted via 
exosomal low-density (LDL) or high-density (HDL) lipoproteins and their load of proteins, cytokines/chemoquines, and microRNAs (miRNAs) [27-30].

Isolation and enrichment of EVs, exosomes in particular, has been cumbersome, despite the several techniques used: ultracentrifugation, density-gradient separation, immunoaffinity capture, microfluidic systems, sequential filtration, and combinations of several techniques [14,29-33]. Of all, the immunoaffinity precipitation and capture provided by several commercial kits (i.e. Exo-Quick-TC, System Biosciences, Mountain View, CA, USA) is probably the easiest method. However, due to the low density and small size of the exosomes, purity is poor and demands additional confirmation by western blotting of exosomal markers, as hsp70 [21]. Gradient ultracentrifugation is more accurate, provided contamination with lipoproteins (LDL/HDL) is considered. Of particular relevance is the knowledge that the HDL also carries miRNAs [29,30,34], requiring differential identification of exosomes and HDL. Exploration of SP-exosomes has been extensive in human presumably because most exosomes are derived from the prostate gland, whose secretion can be specifically retrieved by rectal palpation [2] but research has also been relevant in other mammalian species, including pig [24]. Use of protein markers, as the highly conserved transmembrane-4 superfamily tetraspanins has dominated, associated to the use of ultrafiltration or ultracentrifugation. Tetraspanins CD9 and CD81 can build fusioncompetent sites together with integrins, paying a role in cell-to-cell communication [35]. While CD9 is common to all EVs, CD63 is most often related to microvesicles and CD81 is overrepresented in exosomes, including the in SP of pigs [36]. Tetraspanins as CD9, CD63 and CD81, having a broad tissue distribution are included in most commercial kits to isolate and identify EVs. Other markers, as CD44, the cellsurface glycoprotein receptor for hyaluronan depicts -through multiple CD44 isoforms- 
an ample, diverse biological activity, related to numerous functions and pathologies [37]. The CD44 has until now, however, only been present in EVs / exosomes derived from mesenchymal stem cells [38], related to extracellular matrix [39] and tumoral exosomes [40-42], in relation to the local production/presence of the ligand hyaluronan. CD44 is expressed by numerous cell types including pig spermatozoa [43] but also in the epididymis and prostate [44]. CD44 is yet in pig SP, a complex biofluid, where the possibility of co-isolating exosomes with other vesicles or proteins is very high $[33,45]$. The present study aimed detection of exosomes in pig seminal plasma using FC of EVmarkers (tetraspanins CD9, CD63, CD81), the receptor CD44, western blotting and electron microscopy. Since the pig ejaculates in sequential fractions [1], these were further characterized for exosome and lipoprotein isolation via a two-step discontinuous $\mathrm{KBr}$-density-gradient ultracentrifugation. The location of CD44 was a particularly goal since this is yet to be explored in seminal fluid/SP despite being present in epididymal and prostate secretions which accompanies the emitted spermatozoa, and could thus act as a specific putative biomarker.

\section{Material and methods}

\subsection{Ethics statement}

Animal husbandry and experimental handling were performed in compliance with the European Community (Directive 2010/63/EU) and current Swedish legislation (SJVFS 2017:40). The experiments were approved in advance by the "Regional Committee for Ethical Approval of Animal Experiments" (Linköpings Djurförsöksetiska nämnd) in Linköping, Sweden (permits no. 75-12 and no. ID1400). 


\subsection{Animals}

Young mature boars of Swedish Landrace breed (9-11 months, $n=5)$ with proven sperm quality (concentration, motility and morphology) were recruited from a controlled breeding farm. The animals were individually kept in separate pens at the Translational Medicine Centre (TMC/CBR-3) of Linköping University under controlled temperature and light regimes (12h: 12h light/dark cycle). Pigs were fed with commercial feedstuff (Lantmännen, Stockholm, Sweden) according to national standards [46] provided with water ad libitum and receiving the same management. Throughout all experiments, animals were handled carefully and in such a way to avoid any unnecessary stress.

\subsection{Semen collection, evaluation and harvesting of seminal fluid/plasma (SP)}

To achieve efficient manual collection of semen from the boars, they were properly trained prior to the experiment to mount a stainless steel-made dummy. Both whole ejaculates ( 5 per boar) and specific fractions of the ejaculate, e.g. the sperm-peak fraction (first $10 \mathrm{~mL}$ portion of the sperm-rich fraction, SRF), the rest of the SRF and the post-SRF ( 5 fractionated collections per boar) were manually collected using the gloved-hand method and transferred to pre-warmed plastic tubes. The semen was assessed for sperm concentration and motility (velocity and forward progressive motility) using a light microscope (Axio Scope, Carl Zeiss, Stockholm, Sweden) equipped with a thermal plate (Temp Controller 2000-2, Pecon GmbH, Erbach, Germany) kept at $38{ }^{\circ} \mathrm{C}$, positive phase contrast optics (10x objective), a Charge Coupled Device (CCD) camera (UI-1540LE-M-HQ, Ueye, IDS Imaging Development Systems GmbH, Obersulm, Germany), and the Qualisperm ${ }^{\circledR}$ Software (Biophos SA, 
Lausanne, Switzerland); a high throughput system (usually 4 fields per minute), capable of analyzing $>2000$ spermatozoa/field [47]. Ejaculates with at least $70 \%$ motile and 75\% morphologically normal-looking spermatozoa immediately after collection were used for the experiments.

The samples of the various ejaculate fractions were centrifuged at $10000 \times \mathrm{g}$ at $4{ }^{\circ} \mathrm{C}$ for 10 min (Centrifuge 5424R, Eppendorf AG, Hamburg, Germany). The supernatants (SP) were harvested, checked for absence of spermatozoa, boar- and fraction-wise pooled and stored at $-80{ }^{0} \mathrm{C}$ until analysed.

\subsection{Experimental design}

Seminal plasma samples were examined for exosome contents, identified via transmission electron microscopy, Exo-FLOW ${ }^{\mathrm{TM}}$ Exosome purification beads linked to different antibodies against CD9, CD44, CD63 and CD81 markers (System Biosciences (SBI), 265 North Whisman Rd., Mountain View, CA 94043) and western blotting (WB) using a pig-specific monoclonal antibody (anti-CD44 mouse antibody 60224-1-Ig; Nordic BioSite, Proteintech Europe, Manchester, UK) [43]. Samples examined were those originally centrifuged (see above), following buffer-XE elution or a two-step discontinuous $\mathrm{KBr}$-density-gradient ultracentrifugation procedure $[48,49]$ to harvest three gradients with differential densities of $<1.063$ (F1, coincident with isolation of very low/low density lipoprotein (VLDL/LDL), 1.16-1.21 (F2, for exosomes and highdensity lipoprotein, HDL) respectively 1.21-1.26 g/mL (F3, for exosomes) [50].

\subsubsection{Elution of $S P$}


After a further centrifugation $\left(16000 \times \mathrm{g}\right.$ at $\left.4^{\circ} \mathrm{C}, 10 \mathrm{~min}\right)$, the SP samples were filtered (0.8 $\mu$ m syringe filters; Millipore ${ }^{\circledR}$ Millex ${ }^{\circledR}-A A$, cat. no. SLAA033SB), mixed 1:1 (v/v) with Buffer XBP and the mix placed into the exoEasy spin column (exoRNeasy Serum/Plasma Midi Kit, Cat No./ID: 77044; Qiagen, Sollentuna, Sweden). The column was spun at $500 \mathrm{x}$ g. for $1 \mathrm{~min}$ at rt. The flow-through was discarded, Buffer XWP (3.5 $\mathrm{mL}$ ) replaced and spun at $5000 \times \mathrm{g}$ for $5 \mathrm{~min}$ to remove residual volume from the column. After discarding the flow-through again, Buffer-XE (1 mL, Cat No./ID: 76214; Qiagen, Sollentuna, Sweden), was added to the membrane, incubated for 1 min., recentrifuged at $500 \times \mathrm{g}$ for $5 \mathrm{~min}$ to collect the eluate which was assessed with the ExoFLOW ${ }^{\mathrm{TM}}$ Exosome purification beads, as described below.

\subsubsection{Two-step discontinuous density-gradient ultracentrifugation of seminal plasma}

Exosome fractions, with densities of $<1.063$ (F1), 1.16-1.21 (F2) and 1.21-1.26 g/mL (F3), were isolated from SP using two-step discontinuous $\mathrm{KBr}$-density-gradient ultracentrifugation, as described before [49]. Seminal plasma (4.5 mL) was mixed with $0.5 \mathrm{~mL}$ of EDTA $(10 \mathrm{mg} / \mathrm{mL})$ and sucrose $(5 \mathrm{mg} / \mathrm{mL})$. The $5 \mathrm{ml}$ solution was mixed with $2.072 \mathrm{~g} \mathrm{KBr}$ to a final density of $1.24 \mathrm{~g} / \mathrm{ml}$ and transferred to an ultracentrifugation tube. The solution was overlayered with a $\mathrm{KBr} / \mathrm{PBS}$ solution with the density 1.063 $\mathrm{g} / \mathrm{mL}$. Tubes were sealed and ultracentrifugation was performed at $290000 \times g$ at 15 ${ }^{\circ} \mathrm{C}$ for $4 \mathrm{~h}$ in a Beckman Coulter Ti 70.1 rotor. Exosome fractions, with densities of $<1.063(\mathrm{~F} 1), 1.16-1.21(\mathrm{~F} 2)$ and $1.21-1.26 \mathrm{~g} / \mathrm{mL}(\mathrm{F} 3)$, were aspirated from the tubes with syringes and kept at $-80^{\circ} \mathrm{C}$ until analysis.

\subsubsection{Exosome identification and analysis}


Exosomes were identified using the Exo-FLOW ${ }^{\mathrm{TM}}$ Exosome purification beads (System Biosciences, SBI, Mountain View, CA, USA) linked to biotinylated capture antibody antibodies against the tetraspanins CD9, CD63 and CD81 (EXOFLOW15OA1), and against the receptor CD44 (EXOFLOW21OA-1) following the protocols of the manufacturer. In brief, $40 \mu \mathrm{L}$ streptavidin magnetic bead slurry were placed in $1.5 \mathrm{~mL}$ tubes on a magnetic stand, washed with Bead Wash buffer, attaching the beads on the side of the tube with the magnetic stand. Biotinylated capture antibodies (CD9, CD81, CD63 and CD44) were added, kept on ice for $2 \mathrm{~h}$, then washed with Bead Wash buffer, to be re-attached to the magnetic stand to remove the supernatant and keep the beads now bound with the biotinylated capture antibodies. Concentrated, isolated exosomes $(100 \mu \mathrm{L})$ were added to each bead tube and incubated on a rotating rack at $4^{\circ} \mathrm{C}$ overnight for capture. The samples were placed again on the magnetic stand for $2 \mathrm{~min}$ to carefully remove the supernatant, followed by washing with Bead Wash buffer and a flick to mix. Exosome Stain Buffer $(240 \mu \mathrm{L})$ and $10 \mu \mathrm{L}$ of Exo-FITC exosome stain were added, placing the tubes on ice for 2 hours. Thereafter, the supernatant was removed after replacing tubes for 2 min on the magnetic stand. Following a new wash, samples resuspended in $300 \mu \mathrm{L}$ Bead Wash buffer, were examined by flow cytometry (FC) using a GalliosTM (Beckman Coulter, Bromma, Sweden) instrument equipped with standards optics, violet laser $(405 \mathrm{~nm}) 2$ colours, argon laser $(488 \mathrm{~nm}) 5$ colours and HeNe-laser (633 nm) 3 colours. Filter configuration: Blue: FL1 550SP 525BP (FITC). The instrument is controlled with Navios software (Beckman Coulter, Bromma, Sweden). Analyses of acquired data were performed using the Kaluza software (Beck- man Coulter, Bromma, Sweden) on a separate PC. In all cases we assessed 25,000 events per sample, with a flow rate of 200 particles/s. Bead flow separation data for the various capture antibodies coupled with Exo-FITC staining 
resulted from forward scatter (Height-linear) versus FITC intensity (Average-log), after a primary gating on the majority bead singlets by use of Side Scatter (Average-log) vs. Forward Scatter (Average-linear).

\subsubsection{Western Blot}

Samples of pooled seminal plasma/fluid $(1 \mathrm{~mL})$ were centrifuged $\left(2000 \times g\right.$ at $5{ }^{\circ} \mathrm{C}$ for $30 \mathrm{~min}$ ) and supernatants harvested. Then, $200 \mu \mathrm{L}$ of Total Exosome Isolation Reagent (Invitrogen ${ }^{\mathrm{TM}}$, Waltham, MA USA, Product code: 13355394) were added. After vortexing and refrigeration at $5{ }^{\circ} \mathrm{C}$ for $30 \mathrm{~min}$, samples were centrifuged again $(10,000$ $\times g$ at $5{ }^{\circ} \mathrm{C}$ for $10 \mathrm{~min}$ ) prior to extraction of exosome proteins by incubation in $200 \mu \mathrm{L}$ of RIPA buffer (Sigma-Aldrich). After sonication (Amplitude 60 W, 10 s, 2 cycles), samples were kept at $4^{\circ} \mathrm{C}$ for $40 \mathrm{~min}$. The extracted samples were centrifuged at 13000 $\times g$ for $10 \mathrm{~min}$, and proteins quantified using a DC Protein assay kit (Bio Rad, Hercules, CA, USA), following manufacturer's instructions. Protein suspensions $(0.625 \mu \mathrm{g}$ protein $/ \mu \mathrm{L})$ were denatured by heating at $70^{\circ} \mathrm{C}$ for $10 \mathrm{~min}$. Aliquots $(10 \mu \mathrm{l})$ of each protein suspension were loaded into 4-20\% Mini-PROTEAN® TGX ${ }^{\mathrm{TM}}$ Precast Protein Gels (BIORAD). Electrophoresis was performed at $150 \mathrm{~V}$ for $45 \mathrm{~min}$, followed by transfer of the proteins to Nitrocellulose membranes (LI-COR Biosciences, Lincoln, NE, USA) at $100 \mathrm{~V}$ for $60 \mathrm{~min}$. The membranes were blocked at room temperature for 60 min with Blocking solution (LI-COR Biosciences, Lincoln, NE, USA) and washed in phosphate-buffered saline (PBS) (ThermoFisher Scientific, Waltham, MA, USA) containing 0.1\% Tween-20 (Sigma-Aldrich) (PBST). After three washes of $10 \mathrm{~min}$ in PBST, one membrane was incubated at $4{ }^{\circ} \mathrm{C}$ overnight with the primary monoclonal (1:500 dilution, anti-CD44 antibody 60224-1-Ig; mouse monoclonal antibody to CD44; species specificity: pig; Nordic BioSite, Proteintech Europe, Manchester, UK). The 
specificity of the monoclonal antibody was tested in another membrane by previous coincubation (RT with agitation for one min) of the primary antibody in excess presence (1:5 ratio) of its specific blocking peptide (CD44 Fusion Protein Ag7633, Nordic BioSite, Proteintech Europe, Manchester, UK). The day after, the membrane was washed 3 times in PBST and incubated for 60 min with a dilution 1:15,000 of the secondary antibody (goat anti-mouse IRDye 800 CW (925-32210, LI-COR Biosciences, Lincoln, NE, USA) followed by extensive washing in PBST. The membranes were scanned using the Odyssey CLx (LI-COR Biosciences, Lincoln, NE, USA), and images of the blots were obtained using the Image Studio 4.0 software (LICOR Biosciences, Lincoln, NE, USA).

\subsubsection{Ultrastructure of exosome gradient fractions}

Aliquots $(5 \mu \mathrm{L})$ of the gradient fractions (F1-F3) obtained by two-step discontinuous $\mathrm{KBr}$-density-gradient ultracentrifugation were fixed at room temperature in a $0.1 \%$ (w/v) paraformaldehyde solution $(50 \mu \mathrm{L})$ for at least 18 hours. After washing in distilled water, a five (5) $\mu 1$ drop of the fixed fractions were deposited on 200-mesh EM copper grids with formvar coating, the excess fluid removed by blotting and incubated for 7 minutes at room temperature. The grids were thereafter transferred to $2 \%$ uranyl acetate (w/v) drops for negative staining [51]. Electron micrographs were obtained using a transmission electron microscope (EM JEM 1230, JEOL Ltd., Tokyo, Japan), operated at $100 \mathrm{kV}$. Two-dimensional data was collected and images were processed for assessing the size of the EVs using Image $\mathrm{J}$ (https://imagej.nih.gov/ij/) and RStudio (https://www.rstudio.com) for illustration of the collected summarized data. 


\section{Results}

The flow cytometric sorting procedure was able to clearly separate the distinct particular surface markers for the EVs, see Figs 1-2. Both the pools of uncentrifuged (bulk) and the eluted Buffer XE pooled boar SP showed positive binding/staining to the three tetraspanins tested (CD9, CD63, CD81) and the hyaluronan receptor CD44 (see Fig 2, Table 1). Moreover, this marking was present in each one of the fractions of the boar ejaculate (Sperm-peak/P1, rest of the SRF and the post-SRF) (Table 1). However, the percentages of positive staining were variable among fractions, with the SRF-P1 being the one with the lowest proportion of positive stating, and the P1 having the highest, irrespective of considering tetraspanins or CD44 (Table 1).

When the same fractions of the boar ejaculate were further explored assaying the three density fractions obtained using the two-step discontinuous $\mathrm{KBr}$-density-gradient ultracentrifugation (see Table 2) it became evident that neither the three tetraspanins (CD9+CD63+CD81) nor the CD44 could be detected in the F1-gradient fraction $(<1.063 \mathrm{~g} / \mathrm{mL})$ in any of the ejaculate fractions tested (P1, SRF-P1 and Post-SRF). The other two gradient fractions (F2: 1.16-1.21g/mL, F3: $1.21-1.26 \mathrm{~g} / \mathrm{mL}$ ) showed positive EXO-FLOW results, indicating the presence of exosome-like EVs in all three fractions of the boar ejaculate. Moreover, not only these EVs could be identified as exosomes, but they also consistently marked for CD44.

The ultrastructure of the gradient fractions obtained using the two-step discontinuous KBr-density-gradient ultracentrifugation confirmed the screening performed by the EXO-FLOW mapping (Figs 2 and 3 a) are representative views of tetraspanin and CD44 positive samples (gradients F2 and F3) from the P1-sperm peak ejaculate fraction depicting round or cup-shaped membrane surrounded vesicles containing a content with varying electron-density. An amorphous, often filamentous structures (300-400 
$\mathrm{nm}$ long) were present in various amounts among samples, compatible with protein aggregates, and larger than eventual HDL (usually between 7-13 $\mathrm{nm}$ size). The analysis of the size of the EVs revealed they had an asymmetric size distribution, ranging between 20 and $200 \mathrm{~nm}$ in diameter, with the majority being between 50 and 60nm, e.g. indicative of exosomes (Figs $3 \mathbf{b}$ and d). In comparison (data not shown), the F1-gradient, negative to all tetraspanins and even to CD44, depicted mostly electron-lucent vesicles of very small size, probably corresponding to low-density lipoproteins (LDL), as expected for this particular gradient fraction $(<1.063 \mathrm{~g} / \mathrm{mL})$.

The Western Blot (WB) using the porcine specific anti-CD44 monoclonal antibody (60224-1-Ig) detected the receptor CD44 in the pig seminal plasma from all ejaculated fractions (L1: P1, L2: SRF-P1 and L3: Post-SRF) identifying expected bands at $85 \mathrm{kDa}$, indicative of a full-size CD44 (Lane 1-3, Fig 4a). The bands showed a gradient of relative intensity (L1-3), being most intense in P1 (L1). The co-incubation of the primary antibody with its specific blocking peptide (CD44 Fusion Protein Ag7633) at 1:5 ratio, neutralized the detected CD44 bands (Fig 4b), confirming the specificity of the monoclonal antibody and the presence of CD44 in pig seminal plasma.

\section{Discussion}

In the present study, sperm-free boar seminal plasma was studied using flow cytometry of EXO-FLOW ${ }^{\mathrm{TM}}$ Exosome purification beads incubated with antibodies against a battery of membrane tetraspanins (CD9, CD63 and CD81) and the membrane receptor CD44. The samples examined were either centrifuged bulk SP from three wellcharacterized fractions of the boar ejaculate (P1, SRF-P1 and Post-SRF) or enriched gradient fractions obtained through a two-step discontinuous $\mathrm{KBr}$-density-gradient 
ultracentrifugation procedure. The gradient fractions had three densities $(<1.063 \mathrm{~g} / \mathrm{mL}$, 1.16-1.21g/mL, 1.21-1.26 g/mL) were further examined with transmission electron microscopy. The results confirmed the presence of exosomes in all ejaculate fractions of the boar SP. The two-step discontinuous $\mathrm{KBr}$-density-gradient ultracentrifugation enriched the population of exosomes in two specific gradient fractions, indicating exosomes (either prostasomes or epididymosomes) could be separated from LDL but co-sedimented with the HDL-bearing fraction.

Many methods for isolation of EVs (microvesicles and/or exosomes) have been applied in different fluids and species (reviewed by [29, 51-52]). These techniques include among others ultracentrifugation (serial, stepwise, etc [53]), density-gradient separation, immunoaffinity precipitation and capture, microfluidic systems, sequential filtration etc. Precipitation with following capture is probably the easiest method, commercially offered, easy and quick [21]. However, due to the low density and small size of the exosomes, purity is low-to-poor and demands further screening of exosome surface markers (as hsp70). Ultracentrifugation is more accurate, provided contamination with LDL/HDL is avoided, relevant when isolation/enrichment pursues further studies of the miRNA cargo of the cell vesicles [29,30]. In the present study, we studied samples that were only centrifuged for sperm separation from the SP. Moreover, SP derived from specific fractions of the pig ejaculate were further subjected to a twostep discontinuous KBr-density-gradient ultracentrifugation [49]. The procedure yielded good results, separating very low/low-density lipoprotein (VLDL/LDL) in F1 $(<1.063 \mathrm{~g} / \mathrm{mL})$, from the F2 $(1.16-1.21 \mathrm{~g} / \mathrm{mL})$ where we expected exosomes to be present alongside high-density lipoprotein (HDL) which appeared to co-sediment in F3 $(1.21-1.26 \mathrm{~g} / \mathrm{mL})$. The ultrastructure confirmed the findings, samples being somewhat heterogeneous, i.e. containing both exosomes and microvesicles, with a dominance of 
the first named. The examination of the size of the vesicles and liproproteins confirmed the EVs were within the expected ranges [54].

The finding that while all SP-fractions in pigs were positive for CD9, CD63 and CD81, and even to CD44; and that the P1 (the sperm-peak fraction of the pig ejaculate [1]) was the one yielding the most positive staining, compared to the SRF-P1 substantially disagrees with the results reported by Bai [21] where they, using only Exo-Quick-TC exosomal isolation kit concluded that exosomes were only present in the sperm-rich fraction of the boar ejaculate. The reason for these differences might relate to the type of exosome isolation, which is far from less accurate than the one used hereby. In the present study we further used a more accurate collection of samples, collecting in separate the sperm-peak portion (P1), which represents the bulk of the epidydimal secretion, containing exosomes (epididymosomes). The rest of the SRF, containing more prostate secretion, contained also exosomes (prostasomes). Although we could not determine whether the P1 staining corresponded to epididymosomes or if the SRFP1 had more prostasomes; the distinction is irrelevant, since these are probably similarly carrying the same tetraspanins and even the CD44. Further efforts are needed to made a deeper mapping of the kind of dominating structure and the cargo present, a matter that it is apparently not solvable at present $[26,36,55]$.

Newer flow cytometers, such as those with high resolution and reduced angle flow cytometers allow now for better identification of particles at the nanometre level (i.e. below $40 \mathrm{~nm}$ ) [56]. A very recent study using this instrumentation to examine the SP of pigs (bulk ejaculate) yielded results confirming the EVs present were of heterogenous size, still not allowing for an accurate enrichment of either exosomes or MVs [36]. However, this particular study demonstrated not only that the pig SP contained more exosomes than MVs, but also the existence of some degree of 
selectivity for the tetraspanins among the EVs; i.e. exosomes had more CD9+CD81 compared to MVs, with a predominance of CD81 [36]; yet showing an overlapping of the marking [14]. Further development of discriminative protocols is pre-requisite if studies of the load of these EVs is to be functionally tested [35]. We already know what general cargo they carry, including ncRNAs, and specific proteins [34]. However, not only the EVs carry these molecules; lipoproteins are also carriers with similar delivery capacity for miRNAs, both LDL and particularly HDL [34]. The capacity of the twostep discontinuous $\mathrm{KBr}$-density-gradient ultracentrifugation to clearly separate the LDL fraction (F1) is a major advantage in this respect. However, the apparent cosedimentation of the F2-F3 (exosomes, MVs and HDL) needs to the further separated, a matter to be solved before we can continue with examination of the role their respective cargo may play on spermatozoa (protective role ${ }^{4}$ ) and the female genital tract (signalling for already documented changes in gene expression, including immune process genes $[5,6,21])$. Since exosomes are constituted to a large extent of membrane lipids, further studies are needed to determine their role and to aid in the more accurate isolation and classification of the different EVs $[33,45]$.

Noteworthy was the detection of CD44 in the EVs of the the pig SP, basically in all fractions, and the EV-and HDL- bearing gradient fractions. The CD44 is present in the female and male genital tract, as well as in the cumulus-oocyte complex and the early embryo, often in relation to its character of membrane receptor for the ligand hyaluronan (rev by [57]). It is particularly expressed by the epididymis and the prostate [58], and it is also present in the pig spermatozoon [43]. The presence of CD44 in the EVs of the porcine sperm-free SP would therefore not be a surprise, considering that prostasomes are recruited by and attached to spermatozoa in response to early capacitation events in the uterus and oviduct, and stimulate secondary pathways related 
to hypermotility and acrosome reaction, when approaching the oocyte [49]. However, which specific role the CD44 receptor plays in EVs and or HDL is yet unknown. The CD44 defines action via the ligands involved, as with hyaluronan, but relevant evidence exists coupling the cellular adhesion molecule (CAM)-CD44 with secondary signalling complexes involved in wound healing, angiogenesis and modulation of the immune system [59]; the latter crossing over to pathological status, as development of neoplasias and metastases $[37,60]$, particularly in those where hyaluronan presence or production is confirmed $[59,61]$. EVs containing HA in their surface, often derived from mesenchymal-derived tumours contain CD44, as one of the present CAMs [62], most likely to retain the EV-associated hyaluronan during transport in body fluids (rev by $[59,61])$. The findings of the present study relied initially on using the FC/EXOFLOW platform to identify the presence of CD44 in EVs (microvesicles/exosomes) in specific fractions of the boar ejaculate, with variations in between. We therefore performed a Western blotting to confirm the CD44 presence via a pig-specific monoclonal antibody previously tested, including co-incubation with the immunogenic peptide used to prepare the antibody [43]. The WB confirmed CD44 is present in exosomes in the pig SP, with a variation in relative intensity between the three fractions explored, decreasing from the P1 (most intense) towards the Post-SRF (less intense).

What would then be the meaning of having CD44 present in EVs of the porcine SP? As mentioned before, EVs particularly those in blood plasma and in mesenchyma-derived tumours carry surface-associated hyaluronan probably attached via surface present CD44 [59]. Moreover, this hyaluronan coating of EVs could also regulate interactions of EVs with target cells, for instance the CD44-bearing epithelium of the female genital tract [63]. In the case of the SP, it contains hyaluronan [57] which appears to influence in vitro fertilization of pig oocytes [64], modulating sperm capacitation in vitro [65] 
and in vivo [66], with presence of hyaluronan and CD44 in the oviduct [57]. Such interactions are not surprising, considering surface molecules on EVs would determine the uptake and biological functions of EVs. In this particular case, the presence of CD44 would provide the SP-EVs with a relevant player for interacion with cells of the female genital tract epitelial lining and other molecules in the fluid present in the uterus and oviduct, which is rich in glycosaminoglycans (GAGS), including hyaluronan [67]. EVs from tumoral origin carry sulfated GAG molecules that could bear specific cytokines/chemoquines [59], including TGF- $\beta$, a tolerogenic chemoquine detected in the pig-SP [6] whose gene expression is increased after mating [5]. Such cytokine signalling by the SP would be behind the improved fertility obtained after AI with frozen-thawed semen exposed to SP during freezing or post-thaw [68-71]. Further studies are foreseen to determine the cargo of SP-EVs in relation to their sperm protective function and signalling to the female immune system towards the establishment of a status of maternal immune tolerance to paternal antigens. Of particular interest is the gradient of relative intensity depicted by the WB along the three ejaculate fractions explored. The $\mathrm{P} 1$ is the fraction containing most cauda epididymal fluid accompanyting the peak of spermatozoa ejaculated (25\% of the total sperm numbers in a pig ejaculate [1]). The rest of the SRF contains increasing secretions of particularly the prostate, emission that increases in the Post-SRF, where most of the ejaculate volume is represented by secretion of the prostate and the seminal vesicles, alongside a dramatic decrease of sperm numbers and, per definition the lowest amounts of epididymal fluid. Under these facts, it is pertinent to argument for the possibility that the CD44 relative intensity differing in a similar fashion among the lanes depicted in the WB, might be indicative that the CD44 mainly identifies 
epididymosomes, rather than prostasomes, or even vesiculosomes. Further studies are, however, needed to test this hypothesis.

\section{Conclusion}

EVs, particularly exosomes carrying CD44 are present in the seminal plasma of boars, with differences among specific ejaculate fractions. The two-step discontinuous $\mathrm{KBr}-$ density-gradient ultracentrifugation enriched the population of exosomes/MVs in two specific gradient fractions, indicating exosomes (either prostasomes or epididymosomes) could be separated from LDL but co-sedimented with the HDLbearing fraction. CD44 appears as possible biomarker for the presence of epididymosomes in pig seminal plasma.

\section{Acknowledgments}

Alejandro Vicente-Carrillo and Mohammad Atikuzzaman for their assistance during pig handling and semen collection. We also thank Maria Ntzouni from the Electronmicroscopy and Histology Laboratory, Microscopy Unit, Core Facility at Linköpings University for expert assistance when running the electron microscopy and Cristina A Martinez Serrano for assistance with the Western Blotting.

\section{Author Contributions}

M.A-R., H.K. and H.R-M. designed the experiments. M.A-R. and S.A.L. executed the experiments. M.A-R. performed analyses of data and wrote the first draft of the 
manuscript. All authors read, contributed and approved the final manuscript. M.A-R. and H.R-M. secured funding.

\section{Conflicts of Interest}

The authors declare no conflict of interest. The funders had no role in the design of the study, in the collection, analyses, interpretation of data, in the writing of the manuscript, or in the decision to publish the results.

\section{Funding}

This research was funded by ALF-Research (Region Östergötland, LIO-698951), FORSS (Forskningsrådet i Sydöstra Sverige, Grants 473121 and 745971), Lions Forskningsfond (DNR LIU-2016-00641) and the Swedish Research Council FORMAS (Grant 2017-00946), Stockholm, Sweden. 
Figure 1. Density plots (flow cytometry/EXO-FLOW) of tetraspanins CD9, CD63 and CD81 in the seminal plasma of specific fractions of the boar ejaculate (P1: first $10 \mathrm{~mL}$ of the sperm rich-fraction (SRF); SRF-P1: the rest of the SRF; Post-SRF: the rest of the ejaculate). The dotted line marks the limit between negative (left hand side) and positive (right hand side, \%) plot allocation.

Figure 2. Density plots (flow cytometry/EXO-FLOW) of the CD44 receptor in the sperm-free seminal plasma (SP) of specific fractions of the boar ejaculate (P1: first 10 $\mathrm{mL}$ of the sperm rich-fraction (SRF); SRF-P1: the rest of the SRF; Post-SRF: the rest of the ejaculate). Control: samples not ultracentrifuged, F1-F3: gradients obtained after two-step discontinuous $\mathrm{KBr}$-density-gradient ultracentrifugation $(\mathrm{F} 1:<1.063 \mathrm{~g} / \mathrm{mL}$, coincident with isolation of very low/low density lipoprotein (VLDL/LDL), F2: 1.16$1.21 \mathrm{~g} / \mathrm{mL}$, for exosomes and high-density lipoprotein, HDL) and F3: 1.21-1.26 g/mL (for epididymosomes, co-sedimenting with F2). The dotted line marks the limit between negative (left hand side) and positive (right hand side, \%) plot allocation.

Figure 3 a-d. Transmission electron micrographs of extracellular vesicles (arrows) isolated by two-step discontinuous $\mathrm{KBr}$-density-gradient ultracentrifugation in the gradient fractions F2 (1.16-1.21 g/mL, a), and F3 (1.21-1.26 g/mL, c) of boar seminal plasma from the sperm-peak P1 fraction (first $10 \mathrm{~mL}$ portion of the sperm-rich fraction, SRF), bar $=200 \mathrm{~nm}$. The accompanying histograms in $\mathbf{b}$ and $\mathbf{d}$, depict frequencies of size intervals, indicating the EVs present in the respective fractions were exosomes.

Figure 4 a-b. Western Blot (WB) detection of the receptor CD44 in pig seminal plasma from three porcine ejaculate fractions (L1: P1, L2: SRF-P1 and L3: Post-SRF). a. the porcine specific anti-CD44 monoclonal antibody (60224-1-Ig) identified expected bands at $85 \mathrm{kDa}$ for CD44 in all ejaculated boar fractions (L1-L3). b. Co-incubation of the primary antibody with its specific blocking peptide (CD44 Fusion Protein Ag7633) (1:5 ratio) neutralized the detected bands in L1-L3. 
Table 1. Proportions of flow cytometric FITC-staining (EXO-FLOW) for various extracellular vesicle (EV)-markers (tetraspanins CD9, CD63, CD81 and the receptor CD44) in pooled boar semen fractions (P1: the sperm-peak fraction (first $10 \mathrm{~mL}$ portion of the sperm-rich fraction, SRF), SRF-P1: the rest of the SRF and the post-SRF), testing either the Eluted Buffer XE (CD9) or bulk fractions (CD9, CD63, CD81, CD44). *EXO-FLOW Result: exosome presence +/Absence -.

\begin{tabular}{|c|c|c|c|c|c|}
\hline $\begin{array}{c}\text { EV-surface } \\
\text { marker }\end{array}$ & Sample type & SP fraction tested & FITC- (\%) & FITC+ (\%) & $\begin{array}{c}\text { EXO-FLOW } \\
\text { result* }\end{array}$ \\
\hline $\begin{array}{c}\text { CD9, CD63, } \\
\text { CD81, } \\
\text { CD44 }\end{array}$ & Control, no EVs & - & 99.99 & 0.12 & (1) \\
\hline \multirow[t]{3}{*}{ CD9 } & Eluted Buffer XE & Boar P1 & 0.1 & 99.9 & + \\
\hline & & Boar SRF-P1 & 0.25 & 99.75 & + \\
\hline & & Boar Post-SRF & 0.06 & 99.94 & + \\
\hline \multirow[t]{3}{*}{ CD9 } & Bulk boar SP & $\mathrm{P} 1$ & 0.06 & 99.94 & + \\
\hline & & SRF-P1 & 36.23 & 63.67 & $(+)$ \\
\hline & & Post-SRF & 0.37 & 99.63 & + \\
\hline \multirow[t]{3}{*}{ CD63 } & Bulk boar SP & $\mathrm{P} 1$ & 0.03 & 99.97 & + \\
\hline & & SRF-P1 & 44.25 & 55.75 & $(+)$ \\
\hline & & Post-SRF & 19.69 & 80.31 & + \\
\hline \multirow[t]{3}{*}{ CD81 } & Bulk boar SP & $\mathrm{P} 1$ & 0.03 & 99.97 & + \\
\hline & & SRF-P1 & 25.77 & 74.23 & + \\
\hline & & Post-SRF & 6.58 & 93.42 & + \\
\hline \multirow[t]{3}{*}{ CD44 } & Bulk boar SP & $\mathrm{P} 1$ & 0.07 & 99.93 & + \\
\hline & & SRF-P1 & 40.43 & 59.57 & $(+)$ \\
\hline & & Post-SRF & 11.63 & 88.37 & + \\
\hline
\end{tabular}


Table 2. Proportions of flow cytometric FITC-staining (EXO-FLOW) for various extracellular vesicle markers (tetraspanins CD9, CD63, CD81 and the receptor CD44) in the three density fractions (F1: $<1.063$, F2: 1.16-1.21, F3: 1.21-1.26 g/mL) obtained using the two-step discontinuous KBr-densitygradient ultracentrifugation of boar seminal plasma from three specific ejaculate fractions (P1: the spermpeak fraction (first $10 \mathrm{~mL}$ portion of the sperm-rich fraction, SRF), SRF-P1: the rest of the SRF and the post-SRF, n=3). *EXO-FLOW result: exosome presence +/Absence -.

\begin{tabular}{|c|c|c|c|c|c|}
\hline $\begin{array}{c}\text { EV-surface } \\
\text { marker }\end{array}$ & $\begin{array}{c}\text { Ejaculate } \\
\text { fraction }\end{array}$ & $\begin{array}{c}\text { KBr-density- } \\
\text { gradient }\end{array}$ & FITC- (\%) & $\begin{array}{c}\text { FITC+ } \\
(\%)\end{array}$ & $\begin{array}{c}\text { EXO-FLOW } \\
\text { result** }\end{array}$ \\
\hline $\begin{array}{l}\text { CD9, CD63, } \\
\text { CD81, CD44 }\end{array}$ & Control & - & 99.9 & 0.1 & - \\
\hline \multirow[t]{9}{*}{ CD9 } & P1 & $\mathrm{F} 1$ & 99.67 & 0.33 & - \\
\hline & & $\mathrm{F} 2$ & 0.05 & 99.95 & + \\
\hline & & $\mathrm{F} 3$ & 0.02 & 99.98 & + \\
\hline & SRF-P1 & $\mathrm{F} 1$ & 99.67 & 0.33 & - \\
\hline & & $\mathrm{F} 2$ & 0.08 & 99.92 & + \\
\hline & & F3 & 0 & 100 & + \\
\hline & Post-SRF & $\mathrm{F} 1$ & 99.51 & 0.49 & - \\
\hline & & $\mathrm{F} 2$ & 0.08 & 99.92 & + \\
\hline & & F3 & 0.02 & 99.98 & + \\
\hline \multirow[t]{9}{*}{ CD63 } & $\mathrm{P} 1$ & $\mathrm{~F} 1$ & 98.54 & 1.35 & - \\
\hline & & $\mathrm{F} 2$ & 0.09 & 99.91 & + \\
\hline & & F3 & 0.01 & 99.99 & + \\
\hline & SRF-P1 & $\mathrm{F} 1$ & 99.9 & 0.1 & - \\
\hline & & $\mathrm{F} 2$ & 16.51 & 83.49 & + \\
\hline & & $\mathrm{F} 3$ & 0.27 & 99.73 & + \\
\hline & Post-SRF & $\mathrm{F} 1$ & 99.67 & 0.33 & - \\
\hline & & $\mathrm{F} 2$ & 0.11 & 99.89 & + \\
\hline & & $\mathrm{F} 3$ & 0.09 & 99.91 & + \\
\hline \multirow[t]{9}{*}{ CD81 } & Pool P1 & F1 & 99.91 & 0.09 & - \\
\hline & & $\mathrm{F} 2$ & 0.22 & 99.78 & + \\
\hline & & $\mathrm{F} 3$ & 0.01 & 99.99 & + \\
\hline & SRF-P1 & $\mathrm{F} 1$ & 99.84 & 0.16 & - \\
\hline & & $\mathrm{F} 2$ & 0.03 & 99.97 & + \\
\hline & & F3 & 0 & 100 & + \\
\hline & Post-SRF & $\mathrm{F} 1$ & 99.17 & 0.83 & - \\
\hline & & $\mathrm{F} 2$ & 0 & 100 & + \\
\hline & & F3 & 0 & 100 & + \\
\hline \multirow[t]{9}{*}{ CD44 } & $\mathrm{P} 1$ & F1 & 98.79 & 1.21 & - \\
\hline & & $\mathrm{F} 2$ & 0.09 & 99.91 & + \\
\hline & & F3 & 0.04 & 99.96 & + \\
\hline & SRF-P1 & F1 & 99.61 & 0.39 & - \\
\hline & & $\mathrm{F} 2$ & 0.16 & 99.84 & + \\
\hline & & F3 & 0.01 & 99.99 & + \\
\hline & Post-SRF & $\mathrm{F} 1$ & 99.54 & 0.46 & - \\
\hline & & $\mathrm{F} 2$ & 0.28 & 99.72 & + \\
\hline & & F3 & 0.03 & 99.97 & + \\
\hline
\end{tabular}




\section{References}

[1] Rodriguez-Martinez H, Kvist U, Saravia F, Wallgren M, Johannisson A, Sanz L, et al. The physiological roles of the boar ejaculate. In: Rodriguez-Martinez $\mathrm{H}$, Vallet JL, Ziecik AJ editors. Control of Pig Reproduction VII. Nottingham University Press, UK; 2009. pp 1-21 (ISBN 978-1-904761-39-6).

[2] Samanta L, Parida R, Dias TR, Agarwal A. The enigmatic seminal plasma: a proteomics insight from ejaculation to fertilization. Reprod Biol Endocrinol 2018;16:41. https://doi.org/10.1186/s12958-018-0358-6.

[3] Saravia F, Wallgren, M, Johannisson A, Calvete JJ,L Sanz L, Peña FJ, Roca J, Rodríguez-Martínez H. Exposure to the seminal plasma of different portions of the boar ejaculate modulates the survival of spermatozoa cryopreserved in MiniFlatPacks. Theriogenology 2009;71: 662-675.

[4] Rodriguez-Martinez H, Kvist U, Ernerudh J, Sanz L, Calvete JJ. Seminal plasma proteins: what role do they play? Am J Reprod Immunol 2011;66:11-22. https://doi.org/10.1111/j.1600-0897.2011.01033.x.

[5] Atikuzzaman M, Alvarez-Rodriguez M, Vicente-Carrillo A, Johnsson M, Wright D, Rodriguez-Martinez H. Conserved gene expression in sperm reservoirs between birds and mammals in response to mating. BMC Genomics. 2011;18:98. https://doi.org/10.1186/s12864-017-3488-x.

[6] Alvarez-Rodriguez M, Atikuzzaman M, Venhoranta H, Wright D, RodriguezMartinez H. Expression of immune regulatory genes in the porcine internal genital tract is differentially triggered by spermatozoa and seminal plasma. Int J Mol Sci 2019;20:513. https://doi.org/10.3390/ijms20030513.

[7] Barranco I, Rubér M, Perez-Patiño C, Atikuzzaman M, Martinez EA, Roca J, et al. The seminal plasma of the boar is rich in cytokines, with significant individual and intra-ejaculate variation. Am J Reprod Immunol 2015;74:523-32. https://doi.org/10.1111/aji.12432.

[8] Barranco I, Tvarijonaviciute A, Perez-Patiño C, Alkmin DV, Ceron JJ, Martinez EA, et al. The activity of paraoxonase type 1 (PON-1) in boar seminal plasma and its relationship with sperm quality, functionality, and in vivo fertility. Andrology 2015;3:315-20. https://doi.org/10.1111/andr.309.

[9] Barranco I, Tvarijonaviciute A, Perez-Patiño C, Vicente-Carrillo A, Parrilla I, Ceron $\mathrm{JJ}$ et al. Glutathione Peroxidase 5 is expressed by the entire pig male genital tract 
and once in the seminal plasma contributes to sperm survival and in vivo fertility. PLOS One 2016;11(9):e0162958. https://doi.org/10.1371/journal.pone.0162958.

[10] Perez-Patiño C, Barranco I, Parrilla I, Valero ML, Martinez EA, RodriguezMartinez $\mathrm{H}$ et al. Characterization of the porcine seminal plasma proteome comparing ejaculate portions. J Proteomics 2016;142:15-23. https://doi.org/10.1016/j.jprot.2016.04.026.

[11] Pérez-Patiño C, Parrilla I, Li J, Barranco I, Martínez EA, Rodriguez-Martínez H, et al. The proteome of pig spermatozoa is remodeled during ejaculation. Mol Cell Proteomics 2018;18:41-50. https://doi.org/10.1074/mcp.RA118.000840.

[12] Pérez-Patiño C, Parrilla I, Barranco I, Vergara-Barberán M, Simó-Alfonso EF, Herrero-Martínez JM, et al. A new in-depth analytical approach of the porcine seminal plasma proteome reveals potential fertility biomarkers. J Proteome Res.2018;17:1065-76. https://doi.org/10.1021/acs.jproteome.7b00728.

[13] Jodar M, Soler-Ventura A, Oliva R. Semen proteomics and male infertility. J Proteomics 2017;162:125-34. https://doi.org/10.1016/j.jprot.2016.08.018.

[14] Machtinger R, Laurent LC, Baccarelli AA. Extracellular vesicles: roles in gamete maturation, fertilization and embryo implantation. Hum Reprod Update 2016; 22:182-193. https://doi.org/10.1093/humupd/dmv055.

[15] Aalberts M, Stout TA, Stoorvogel W. Prostasomes: extracellular vesicles from the prostate. Reproduction 2014;147:R1-14. https://doi.org/10.1530/REP-13-0358.

[16] Nieuwland R, Falcon-Perez JM, Soekmadji C, Boilard E, Carter D, Buzas EI. Essentials of extracellular vesicles: posters on basic and clinical aspects of extracellular vesicles. J Extracell Vesicles 2018;7:1548234. https://doi.org/10.1080/20013078.2018.1548234.

[17] Armstrong D, Wildman DE. Extracellular vesicles and the promise of continuous liquid biopsies. J Pathol Translat Med 2018;52:1-8. https://doi.org/10.4132/jptm.2017.05.21.

[18] Zhang W, Jiang X, Bao J, Wang Y, Liu H, Tang L. Exosomes in pathogen infections: A bridge to deliver molecules and link functions. Front Immunol 2018;9:90. https://doi.org/10.3389/fimmu.2018.00090.

[19] Sullivan R, Saez F. Epididymosomes, prostasomes, and liposomes: their roles in mammalian male reproductive physiology. Reproduction 2013;146:R21-35. https://doi.org/10.1530/REP-13-0058. 
[20] Höög JL, Lötvall J. Diversity of extracellular vesicles in human ejaculates revealed by cryo-electron microscopy. J Extracell Ves 2015;4:28680. https://doi.org/10.3402/jev.v4.28680.

[21] Bai R, Latifi Z, Kusama K, Nakamura, Shimada M2, Imakawa K. Induction of immune-related gene expression by seminal exosomes in the porcine endometrium. Biochem Biophys Res Commun 2018;495:1094-101. https://doi.org/10.1016/j.bbrc.2017.11.100.

[22] Arienti G. Carlini E, Palmerini CA. Fusion of human sperm to prostasomes at acidic pH. J Memb Biol 1997;155:89-94. https://doi.org/10.1007/s002329900160.

[23] Curry E, Safranski TJ, Pratt SL. Differential expression of porcine sperm microRNAs and their association with sperm morphology and motility. Theriogenology 2011;76:1532-39. https://doi.org/10.1016/j.theriogenology.2011.06.025.

[24] Piehl LL, Fischman ML, Hellman U, Cisale H, Miranda PV. Boar seminal plasma exosomes: effect on sperm function and protein identification by sequencing. Theriogenology 2013;79:1071-82. https://doi.org/10.1016/j.theriogenology.2013.01.028.

[25] Caballero JN, Frenette G, Belleannée C, Sullivan R. CD9-positive microvesicles mediate the transfer of molecules to bovine spermatozoa during epididymal maturation. PLoS One 2013;8:e65364. https://doi.org/10.1371/journal.pone.0065364.

[26] Du J, Shen J, Wang Y, Pan C, Pang W, Diao H, et al. Boar seminal plasma exosomes maintain sperm function by infiltrating into the sperm membrane. Oncotarget 2016;7:58832-47. https://doi.org/10.18632/oncotarget.11315.

[27] Belleannée C, Calvo E, Thimon V, Cyr DG, Légaré C, Garneau L, et al. Role of microRNAs in controlling gene expression in different segments of the human epididymis. PLoS One 2012;7:e34996. https://doi.org/10.1371/journal.pone.0034996.

[28] da Silveira JC, de Ávila ACFCM, Garrett HL, Bruemmer JE, Winger QA, Bouma GJ. Cell-secreted vesicles containing microRNAs as regulators of gamete maturation. J Endocrinol 2018;236:R15-R27. https://doi.org/10.1530/JOE-170200 . 
[29] Coumans FAW, Brisson AR, Buzas EI, Dignat-George F, Drees EEE, ElAndaloussi S et al. Methodological Guidelines to Study Extracellular Vesicles. Circ Res. 2017 May 12;120:1632-1648. doi: 10.1161/CIRCRESAHA.117.309417.

[30] Michell DL, Allen RM, Landstreet SR, Zhao,S, Toth CL, Sheng Q, Vickers KC. Isolation of high-density lipoproteins for non-coding small RNA quantification. Journal of Visual Experiments 2016;117:54488. https://doi.org/10.3791/54488

[31] Théry C, Amigorena S, Raposo G, Clayton A. Isolation and characterization of exosomes from cell culture supernatants and biological fluids. Curr Protocols Cell Biol. 2006; Chapter 3: Unit 3.22:1-29. https://doi.org/10.1002/0471143030.cb0322s30.

[32] Greening DW, Xu R, Ji H, Tauro BJ, Simpson RJ. A protocol for exosome isolation and characterization: evaluation of ultracentrifugation, density-gradient separation, and immunoaffinity capture methods. Methods Mol Biol 2015;1295:179-209. https://doi.org/10.1007/978-1-4939-2550-6_15.

[33] Skotland T, Hessvik NP, Sandvig K, Llorente A. Exosomal lipid composition and the role of ether lipids and phosphoinositides in exosome biology. J Lipid Res 2018;60:9-18. https://doi.org/10.1194/jlr.R084343.

[34] Vickers KC, Palmisano BT, Shoucri BM, Shamburek RD, Remaley AT. MicroRNAs are transported in plasma and delivered to recipient cells by highdensity lipoproteins. Nat Cell Biol 2011;13:423-33. https://doi.org/10.1038/ncb2210.

[35] Andreu Z, Yáñez-Mó M. Tetraspanins in extracellular vesicle formation and function. Front Immunol 2014;5:442. https://doi.org/10.3389/fimmu.2014.00442.

[36] Barranco, I. et al. Extracellular vesicles in porcine seminal plasma depict differential tetraspanin expression. (Submitted for publication: 2019).

[37] Jordan AR, Racine RR, Hennig MJ, Lokeshwar VB. The role of CD44 in disease pathophysiology and targeted treatment. Frontiers Immunol 2015;6:182. https://doi.org/10.3389/fimmu.2015.00182.

[38] Arasu UT, Kärnä R, Härkönen K, Oikari S, Koistinen A, Kröger H, et al. Human mesenchymal stem cells secrete hyaluronan-coated extracellular vesicles. Matrix Biol 2017;64:54-68. https://doi.org/10.1016/j.matbio.2017.05.001.

[39] Nawaz M, Shah N, Zanetti BR, Maugeri M, Silvestre RN, Fatima F, et al. Extracellular vesicles and matrix remodeling enzymes: the emerging roles in 
extracellular matrix remodeling, progression of diseases and tissue repair. Cells 2018;7:167. https://doi.org/10.3390/cells7100167.

[40] Tauro BJ, Greening DW, Mathias RA, Mathivanan S, Ji H, Simpson RJ. Two distinct populations of exosomes are released from LIM1863 colon carcinoma cellderived organoids. Mol Cell Proteom 2013;12:587-98. https://doi.org/10.1074/mcp.M112.021303.

[41] Harshman SW, Canella A, Ciarlariello PD, Agarwal K, Branson OE, Rocci A, et al. Proteomic characterization of circulating extracellular vesicles identifies novel serum myeloma associated markers. J Proteomics 2016;136:89-98. https://doi.org/10.1016/j.jprot.2015.12.016.

[42] Nakamura K, Sawada K, Kinose Y, Yoshimura A, Toda A, Nakatsuka E, et al. Exosomes promote ovarian cancer cell invasion through transfer of CD44 to peritoneal mesothelial cells. Mol Cancer Res 2016;15:78-92. https://doi.org/ 10.1158/1541-7786.MCR-16-0191.

[43] Alvarez-Rodriguez M, Vicente-Carrillo A, Rodriguez-Martinez H. Hyaluronan does not improve long-term storage nor cryo-survival of CD44-bearing boar spermatozoa. J Reprod Dev 2018;64:351-60. https://doi.org/10.1262/jrd.2017-141.

[44] Alam TN, O'Hare MJ, Laczkó I, Freeman A, Al-Beidh F, Masters JR, et al. Differential expression of CD44 during human prostate epithelial cell differentiation. J Histochem Cytochem 2004;52:1083-90. https://doi.org/10.1369/jhc.4A6256.2004.

[45] Piehl LL, O Cisale H, Torres N, Capani F, Sterin-Speziale N, Hager N. Biochemical characterization and membrane fluidity of membranous vesicles isolated from boar seminal plasma. Anim Reprod Sci 2006; 92:401-10. https://doi.org/10.1016/j.anireprosci.2005.06.005.

[46] Simonsson, A. Näringsrekommendationer och fodermedelstabeller till svin (Nutrient and metabolizable energy recommendations for swine, in Swedish). Publisher: Swedish University of Agricultural Sciences, SLU Rapporter Husdjur, Sweden 1991.75 pp.

[47] Tejerina F, Buranaamnuay K, Saravia F, Wallgren M, Rodriguez-Martinez H. Assessment of motility of ejaculated, liquid-stored boar spermatozoa using computerized instruments. Theriogenology 2008;69:1129-38.

[48] Yuana Y, Levels J, Grootemaat A, Sturk A, Rienk Nieuwland R. Co-isolation of extracellular vesicles and high-density lipoproteins using density gradient 
$\begin{array}{llll}\text { ultracentrifugation. } & \mathrm{J} & \text { Extracell } & \text { Vesicles }\end{array}$ https://doi.org/10.3402/jev.v3.23262.

[49] Karlsson H, Leanderson P, Tagesson C, Lindahl M. Lipoproteomics II: mapping of proteins in high-density lipoprotein using two-dimensional gel electrophoresis and mass spectrometry. Proteomics 2005;5:1431-45. https://doi.org/10.1002/pmic.200401010.

[50] Aalberts M, Sostaric E, Wubbolts R, Wauben MW, Nolte-'t Hoen EN, Gadella BM, et al. Spermatozoa recruit prostasomes in response to capacitation induction. Biochim Biophys Acta 2013;1834:2326-35. https://doi.org/10.1016/j.bbapap.2012.08.008.

[51] Cizmar P, Yuana Y. Detection and Characterization of Extracellular Vesicles by Transmission and Cryo-Transmission Electron Microscopy. Methods Mol Biol. 2017;1660:221-232. doi: 10.1007/978-1-4939-7253-118.

[52] Konoshenko MY, Lekchnov EA, Vlassov AV, Laktionov PP. Isolation of Extracellular Vesicles: General Methodologies and Latest Trends. Biomed Res Int 2018;2018:854534. https://doi.org/10.1155/2018/8545347.

[53] Momen-Heravi F. Isolation of Extracellular Vesicles by Ultracentrifugation. Methods Mol Biol 2017;1660:25-32. https://doi.org/10.1007/978-1-4939-7253$1 \_3$.

[54] García-Rodríguez A, de la Casa M, Peinado H, Gosálvez J, Roy R. Human prostasomes from normozoospermic and non-normozoospermic men show a differential protein expression pattern. Andrology 2018;6:585-96. https://doi.org/10.1111/andr.12496.

[55] Yang C, Guo WB, Zhang WS, Bian J, Yang JK, Zhou QZ, et al. Comprehensive proteomics analysis of exosomes derived from human seminal plasma. Andrology 2017;5:1007-15. https://doi.org/10.1111/andr.12412.

[56] Morales-Kastresana A, Telford B, Musich TA, McKinnon K, Clayborne C, Braig Z, et al. Labeling extracellular vesicles for nanoscale flow cytometry. Sci Reports 2017;7:1878. https://doi.org/10.1038/s41598-017-01731-2.

[57] Rodriguez-Martinez H, Tienthai P, Atikuzzaman M, Vicente-Carrillo A, Rubér M, Alvarez-Rodriguez M. The ubiquitous hyaluronan: functionally implicated in the oviduct? Theriogenology 2016;86:182-6. https://doi.org/10.1016/j.theriogenology.2015.11.025. 
[58] Castellà Fernández E. Estudio de la expresión de CD44 en procesos preneoplásicos y neoplásicos de esófago, estómago y páncreas. Doctoral Thesis. Universitat Autònoma de Barcelona, Barcelona, Spain. 2000. ISBN846890036. Available from: http://hdl.handle.net/10803/4227.

[59] Buzás EI, Tóth EÁ, Sódar BW, Szabó-Taylor KÉ. Molecular interactions at the surface of extracellular vesicles. Semin Immunopathol 2018;40:453-64. https://doi.org/10.1007/s00281-018-0682-0.

[60] Birzele F, Voss E, Nopora A, Honold K, Heil F, Lohmann S, et al. CD44 isoform status predicts response to treatment with anti-CD44 antibody in cancer patients. Cancer Clin Res 2015;21:2753-62. https://doi.org/10.1158/1078-0432.CCR-142141.

[61] Rilla K, Siiskonen H, Tammi M, Tammi R. Hyaluronan-coated extracellular vesicles-A novel link between hyaluronan and cancer. In: Melanie A. Simpson and Paraskevi Heldin, eds, Advances in Cancer Research. Burlington: Academic Press; 2014. Vol. 123, Ch 5, pp.121-148.

[62] Choi DS, Kim DK, Kim YK, Gho YS. Proteomics, transcriptomics and lipidomics of exosomes and ectosomes. Proteomics. 2013;13:1554-71. https://doi.org/10.1002/pmic.201200329.

[63] Tienthai P, Yokoo M, Kimura N, Heldin P, Sato E, Rodriguez-Martinez H. Immunohistochemical localization and expression of the hyaluronan receptor CD44 in the porcine oviductal epithelium during oestrus. Reproduction 2003;125:119-32. https://doi.org/10.1530/rep.0.1250119.

[64] Suzuki K, Eriksson B, Shimizu H, Nagai T, Rodriguez-Martinez H. Effect of hyaluronan on monospermic penetration of porcine oocytes fertilized in vitro. Int $J$ Androl 2000;23:13-21. https://doi.org/10.1046/j.1365-2605.2000.t01-1-00198.x.

[65] Suzuki K, Asano A, Eriksson B, Niwa K, Nagai T, Rodriguez-Martinez H. Capacitation status and in vitro fertility of boar spermatozoa: Effects of seminal plasma, cumulus-oocytes-complexes-conditioned medium and hyaluronan. Int J Androl 2002;25:84-93. https://doi.org/10.1046/j.1365-2605.2002.00330.x.

[66] Tienthai P, Johannisson A, Rodríguez-Martínez H. Sperm capacitation in the porcine oviduct. Anim Reprod Sci 2004;80:131-46. https://doi.org/10.1016/S03784320(03)00134-9. 
[67] Tienthai P, Kjellén L, Pertoft H, Suzuki K, Rodriguez-Martinez H. Localization and quantitation of hyaluronan and sulfated glycosaminoglycans in the tissues and intraluminal fluid of the pig oviduct. Reprod Fert Dev 2000;12:173-82. https://doi.org/10.1071/RD00034.

[68] Rodríguez-Martinez H, Saravia F, Wallgren M, Roca J, Peña FJ. Influence of seminal plasma on the kinematics of boar spermatozoa during freezing. Theriogenology 2008;70: 1242-1250 (doi:10.1016/j.theriogenology.2008.06.007).

[69] Eriksson BM, Petersson H, Rodriguez-Martinez H. Field fertility with exported boar semen frozen in the new FlatPack container. Theriogenology 2002; 58: 1065 1079.

[70] Li J, Roca J, Pérez-Patiño C, Barranco I, Martinez EA, Rodriguez-Martinez H, Parrilla I. Is boar sperm freezability more intrinsically linked to spermatozoa than to the surrounding seminal plasma? Anim Reprod Sci 2018; doi: 10.1016/j.anireprosci.2018.05.002. [Epub ahead of print].

[71] Recuero S, Fernandez-Fuertes B, Bonet S, Barranco I, Yeste M. Potential of seminal plasma to improve the fertility of frozen-thawed boar spermatozoa. Theriogenology. 2019 May 31. pii: S0093-691X(19)30173-6. doi: 10.1016/j.theriogenology.2019.05.035. [Epub ahead of print] 
Figure 1.

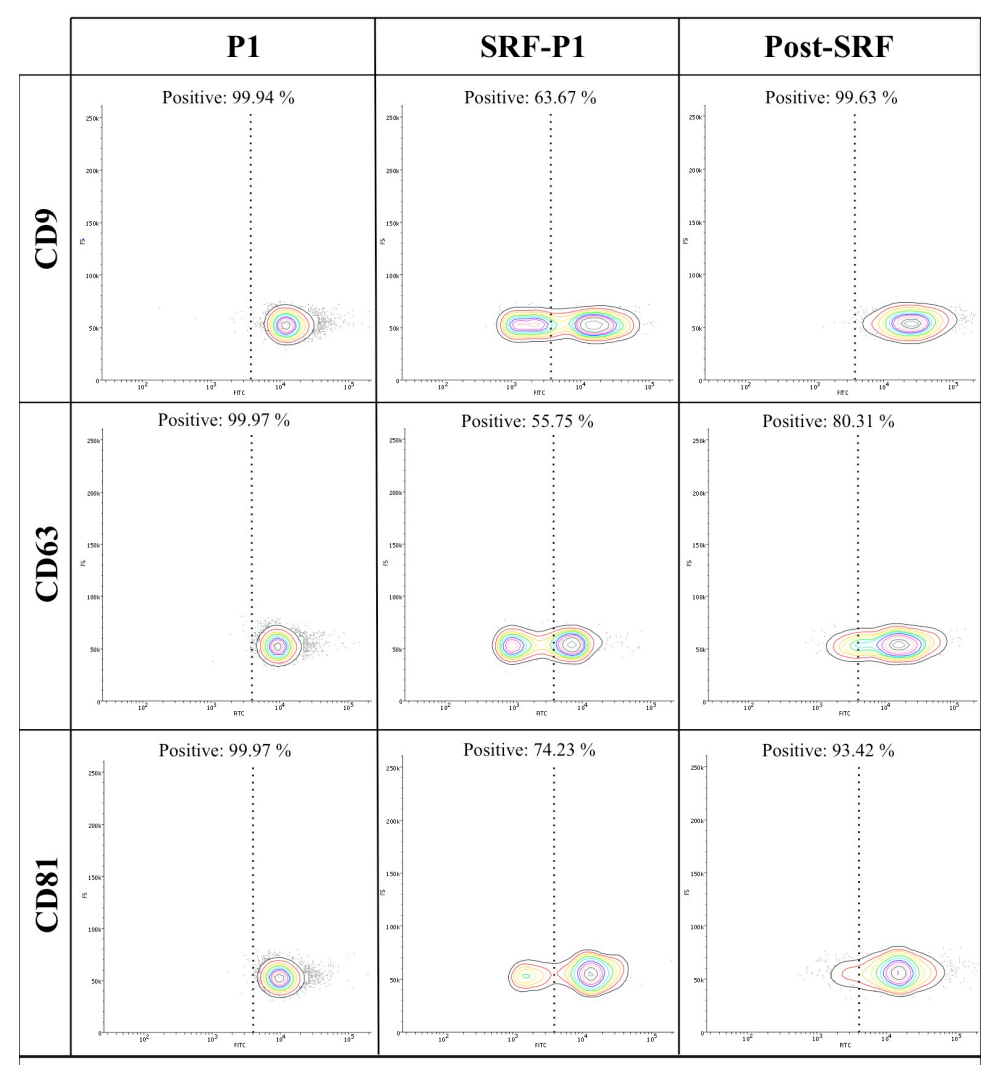

Figure 2.

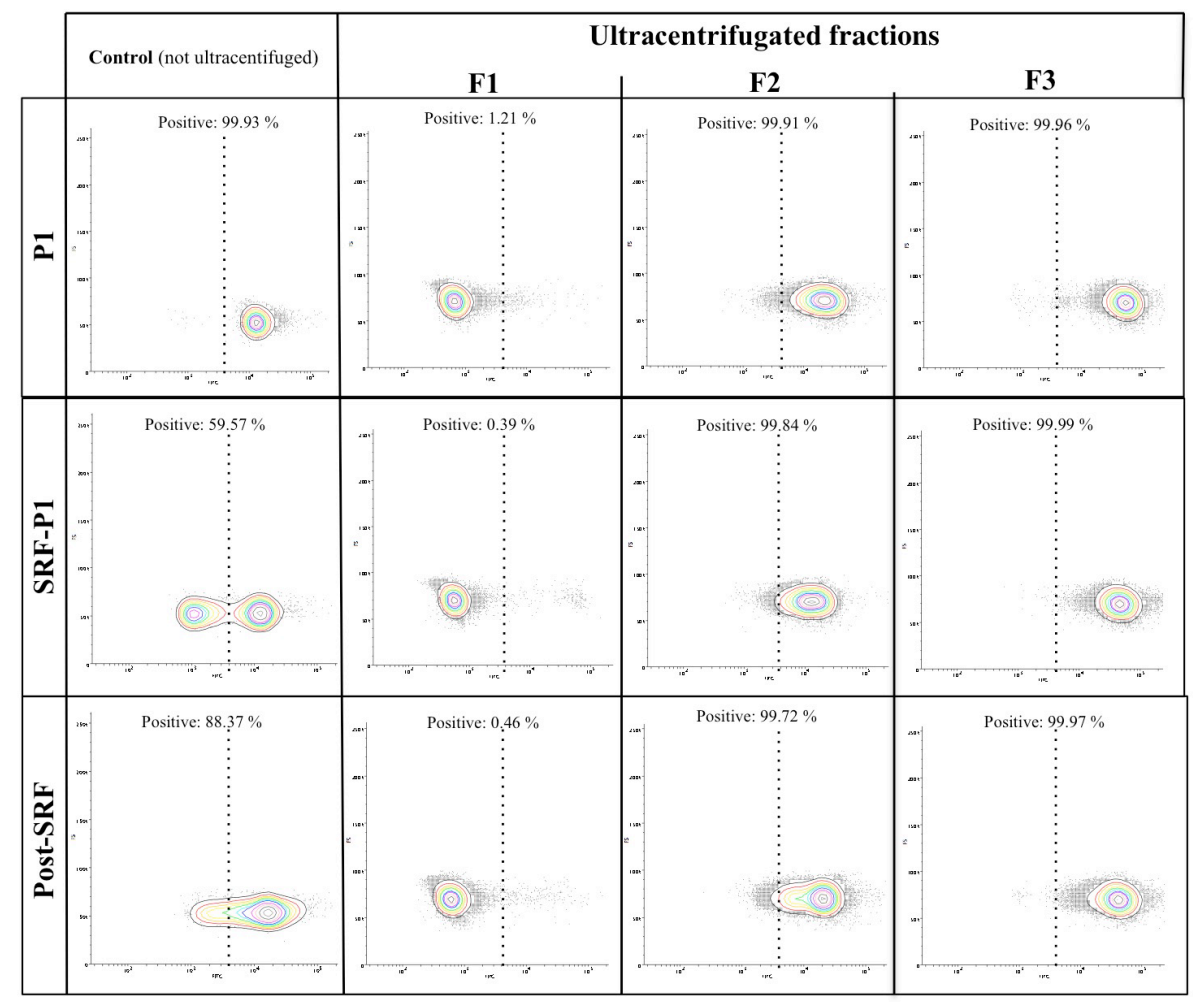


Figure 3.
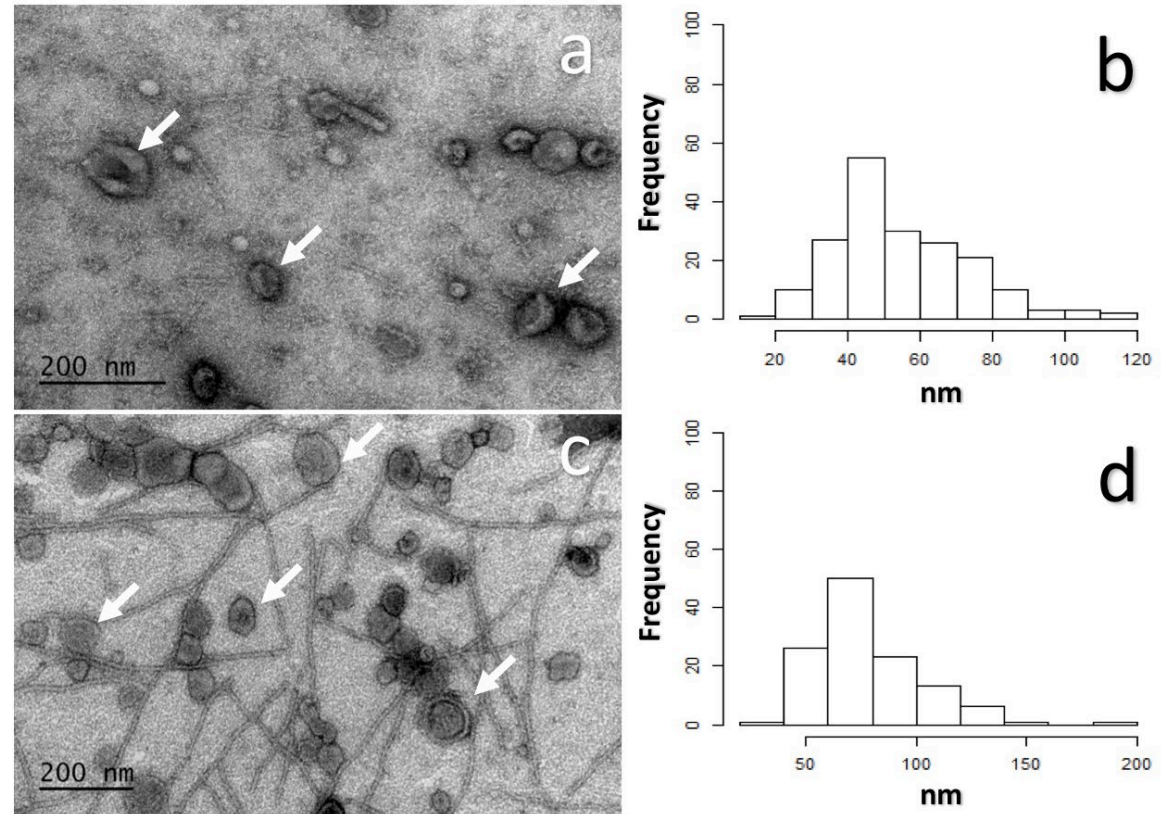

Figure 4.

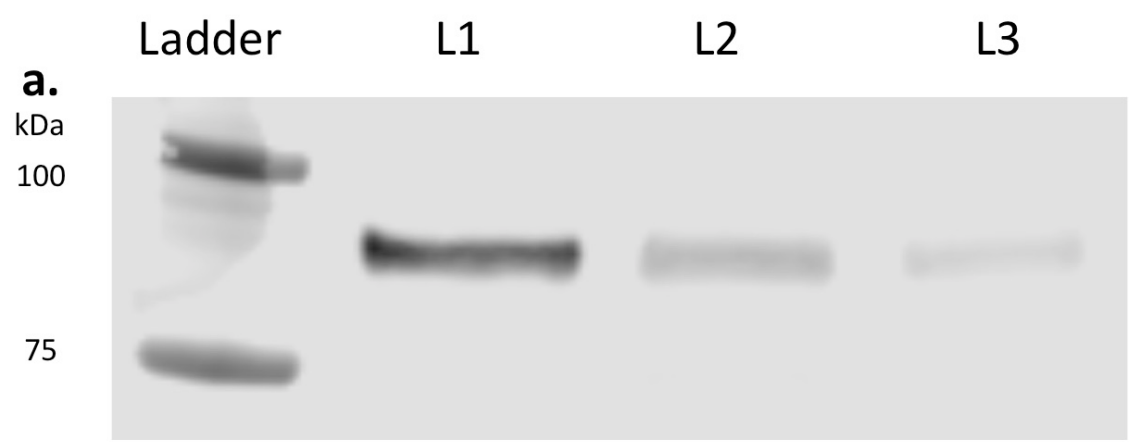

b.

100

75 